\title{
Drop Weight Impact Studies on Rib-Knit RTM Laminates
}

\author{
B. S. SEGUN AND R. M. V. G. K. RAO' \\ FRP Pilot Plant \\ National A erospace Laboratories \\ Bangalore, India
}

\begin{abstract}
Six types of weft rib knit preforms developed on a flat bed hand knitting machine from E-glass rovings of 300Tex have been used in this study. RTM laminates prepared from these six preforms were drop weight tested using a Dynatup CRC model with 830-1 data acquisition software. Glass/epoxy woven fabric composites with varied lay-up sequences were used for comparison and evaluation with these knit laminates under identical test conditions. Laminates from knits 'with' added reinforcements in the course direction have clearly exhibited characteristic failure modes and superior energy absorbing capabilities as compared to the corresponding woven counterparts.
\end{abstract}

KEY WORDS: kcs, RTM laminates, impact behaviour, reinforcements, lay-upcsequences.

\section{INTRODUCTION}

" $v_{1} "$

MPACTDAMAgF.p_i iAV1OUR of composite laminates is fast becoming a studx'pai rameter for evolzying design criteria of aerospace and non-aerospace structures. This is more due_to the detrimental effects that the impact damage envisages On the structure fabricated out of polymeric composite materials. Unlike the observations made on metals, one of the pre-dominant modes of damage in woven fabric composites identified by various researchers [2-4] (using various reinforcement/resin systems) has been delamination/fibre de-bonding. The lack of viable alternative substitutes have forced researchers to consider the delamination problem into the models developed related to impact and compression-after-impact behaviour [5-7]. In the present work, the impact behaviour of rib knit laminates with added reinforcements in the course direction has been evaluated and compared with equivalent woven fabric composites (comprising positional variations and orientation of plies) under identical test conditions.

Author to whom correspondence should be addressed. 


\section{EXPERIMENTAL}

Six types of weft rib knitted preforms (1) with varied reinforcement in the course direction were obtained from a 5" gauge flat-bed hand-knitting machine. The reinforcements comprised of inserting E-glass yarns of varied Tex (1800, $3600,5400,7200$ and 9000) between successive rows of loops. The first preform was a plain knit without any reinforcement.

Step-post cured $\left(50^{\circ} \mathrm{C} 170^{\circ} \mathrm{C} / 85^{\circ} \mathrm{C}\right) \mathrm{RTM}$ laminates prepared from these six preforms were used for impact damage studies with a bi-functional epoxy resin system as the matrix. Parallel comparative evaluation with $3 \mathrm{~mm}$ thick, 12 layered, eight- 2 X 2 twill woven fabric composite laminates were camed out. These laminated were prepared with the same resin system as those used in the case of knits at the standardised fibre weight fraction (WI) of $0.65 \pm 0.02$. The stacking sequence (positional variation of $45^{\circ}$ plies) of the woven fabric composites used in the study were as follows (orientation denoted with reference to warp yarns): $\left[{ }^{4} 5 / 0 \mathrm{~s}\right) \mathrm{t}$, $[0 / 45 / 0],,,\left[0, / 45 / 0_{3}\right],,\left[0_{3} / 45 / 0,\right],,\left[0_{4} / 45 / 0\right],,\left[0_{5} / 45\right],,\left[0_{6}\right]$, ad $[0, / \pm 30 / \pm 45]$, . The laminates-were all of 3 ---.,--, 0.02 min thick prepared by pre-cornpaction by vacuum followed by compression moulding technique using spacers for thickness control. Thus, in all, 14 laminates (viz., 6 knits and 8 wovens) of 90 mill x 90 min were utilised for drop weight studies.

Drop-weight instrumented impact testing machine from Dynatup"Inc., with an 830-I date acquisition software has been used for impacting the specimens. Impactin vas carried out using a hemispherical nosed tup (12.7 mm'_dia ') with an itnpact velocity 3.32 -'_- $0.01 \mathrm{mfrs} / \mathrm{sec}$ and incident energy of $66.6 \pm \mathrm{Q}: 3 \mathrm{~J}$. 'I he incident enemy of $66.6 \pm \mathbf{0 . 3} \mathbf{~ J}$ was chosen arbitrarily to impact the spcdImens with a surplus., o energy than actually required for total penetrationriiflard copy of load-energy plots computed on a time scale by the data-acquisition software has been obtained for all 14 laminates. Before obtaining the plots. they were distinctly marked with different impact events as outlined in Reference [8].

\section{RESULTS AND DISCUSSIONS}

Figure 1 shows a typical trace of an impact event characterised [8] by the following four events:

- Incipient Damage Point (IDP; $E$;, $P$,): Detectable by the first sudden drop and/or change of slope in the ascending portion of the load vs. time curve.

- Maximum Load Point (MLP; E,,, P,,,): 1 he peak load value that a panel can tolerate.

- Failure Point (FP; $\left.E_{f} P_{f}\right)$ : The point where the load starts to drop to the zero load level (or minimum load level after the MLP) with a constant slope.

- Total Point (TP; $E_{\mid}, P$,): The point where the impact event ends (i.e., end of the duration time), arid load returns to zero. 


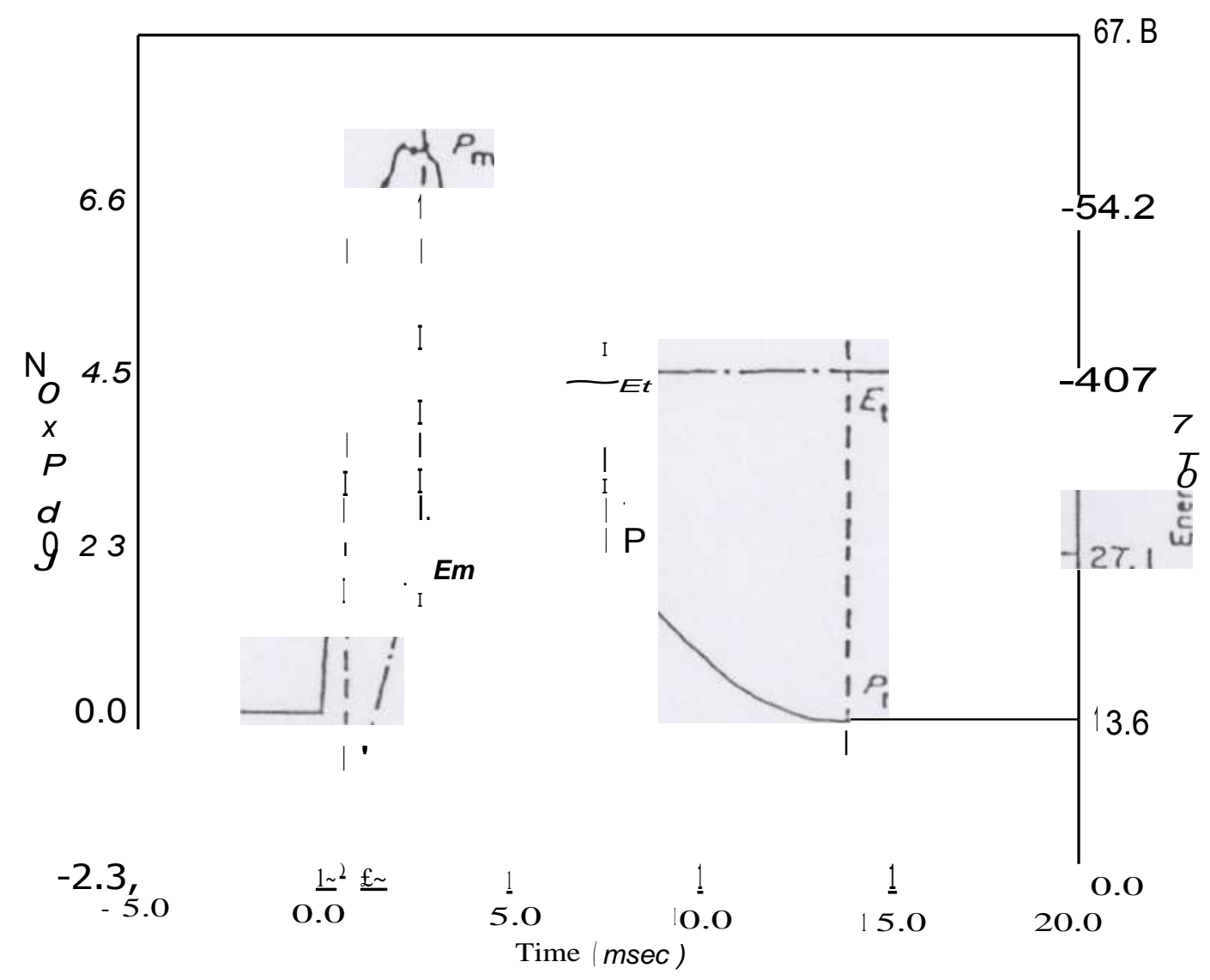

Figure 1. A typical load energy curve obtained from instrumented impact test machine-identification of impact event phases, $j 8 /$.

All 14 laminates were characteriscd'on the above mentioned lines. It should be noted that in some cases IDP occurs" very near to MLP signifying the initial fibre breakage occurring at the peak value ofthe panel.

Tables 1 and 2 show the values compiled for the various impact.cvents from the obtained plots for both woven fabric composites and knit composites respectively.

Figures 2-5 show the load-energy traces of the woven fabric composites and the knitted laminates respectively. While the curves in the case of woven fabric com-

Table 1. Data compiled from the plots for woven fabric composites.

\begin{tabular}{cccc}
\hline $\begin{array}{c}\text { Lay-Up } \\
\text { Sequence }\end{array}$ & $\begin{array}{c}\text { Energy Absorbed } \\
\text { during MLP }\end{array}$ & $\begin{array}{c}\text { Energy Absorbed } \\
\text { during FP }\end{array}$ & $\begin{array}{c}\text { Total Energy } \\
\text { Absorbed }\end{array}$ \\
\hline$\left[45 / 0_{s} 1\right.$, & 20.823 & 33.089 & 53.443 \\
{$\left[0 / 45 / 0_{4}\right]$,} & 22.739 & 34.156 & 55.880 \\
{$\left[0_{2} / 45 / 0_{3} 1\right.$,} & 20.979 & 35.584 & 57.045 \\
{$\left[0_{3} / 45 / 0_{2} 1\right.$,} & 26.234 & 32.150 & 54.841 \\
{$\left[0_{4} / 45 / 0\right]$,} & 25.042 & 48.603 & 57.052 \\
{$\left[0_{5} / 45\right) \mathrm{s}$} & 21.750 & 35.448 & 57.092 \\
$\left.\right|^{0} 61$, & 23.812 & 36.898 & 56.058 \\
$\left.10_{2} 1 \pm 30 / \pm 45\right]_{5}$ & 20.703 & 37.189 & 52.536 \\
\hline
\end{tabular}


Table 2. Data compiled from the plots for knit composites.

\begin{tabular}{cccc}
$\begin{array}{c}\text { Reinforcement } \\
\text { Details (Tex Count } \\
\text { In Course Direction) }\end{array}$ & $\begin{array}{c}\text { Energy } \\
\text { Absorbed } \\
\text { during MLP }\end{array}$ & $\begin{array}{c}\text { Energy } \\
\text { Absorbed } \\
\text { during FP }\end{array}$ & $\begin{array}{c}\text { Total } \\
\text { Energy } \\
\text { Absorbed }\end{array}$ \\
\hline Knit Plain & 16.417 & 25.485 & 32.946 \\
Knit 1800 & 12.971 & 28.623 & 35.550 \\
Knit 3600 & 23.510 & 30.761 & 44.049 \\
Knit 5400 & 30.740 & 43.847 & 49.479 \\
Knit 7200 & 35.544 & 53.360 & 59.977 \\
Knit 9000 & 35.701 & 53.990 & 56.195 \\
\hline
\end{tabular}

posites for varied sequences appear to be smooth, the same is not observed in the case of knits. In the case of knits, the curves show extensive kinks with progressive smoothing as the reinforcement in the course direction is increased. Since all the knit laminates were confined to a defined cubic space during preparation, this resulted in increased matrix content in the reverse orders viz., with the plain knit having_the_maxicnuni.ittatrixcontent...The.kinks observed on the curves thus denote the extensive matrix cracking phenomenon which obviously wanes off with increasing reinforcements.

Figure 6(a) shows the comparative plot of knits and wovens on the energy scale. The plot shows the total energy absorbed by the laminates for the above-defined incident energy. It can be clearly seen that the 7200 Tex reinforced rib knit larninate supersedes all the lay-up sequences of woven fabric composite laminates. Figure 6(b) shows the same data in the form of a column diagram.

Figure 7(a) shows the plot of the energy absorbed by the laminates at MLP. Knits with 3000 Tex reinforcement and above in the course direction surpass the different lay-up sequences of woven fabric composites. Figure 7(b) shows the same data in the form of a column diagram.

Figure 8(a) shows the energy absorbed by the laminates at failure point. The failure point being an observed value (subjective), slight variations may be inherent. Nevertheless, it can be seen that for around 3000 Tex and above reinforcement, the energy absorbing capabilities of knit laminates are superior to those of their woven counterparts. Figure 8(b) shows the column diagram at failure point.

Figures 9 and 10 show the selective photographs of the impacted specimens. In Figure 9, the woven fabric composite (left) is photographed with knit (right). The photograph displays more damage in the case of knits due to the matrix cracking beyond the tup zone. Figure 10 shows the photograph of two extremities in knit composites viz., plain (left) and 9000 Tex reinforcement in the course direction (right). The change-over of geometry from circular to elliptical can clearly be seen.

A visual observation of the damage modes observed in the impacted laminates of wovens and knits is made as shown in Table 3. 
Table 3.

Woven Fabric Laminates

Local delamination in the impact zone is observed in all the Iaminates

Protruding of fibres on the backside of the Impact surface is around 8.5 to $11 \mathrm{~mm}$ in length

Slight propagation of damage beyond the tup zone is observed in almost all the laminates

\section{Rib Knit Laminates}

Rupture of knit configuration is observed in the knit zone and at the tup contact point

Projection of the ruptured knit configurations on the backside of the impact surface is around 7 to $9 \mathrm{~mm}$ long

Matrix cracking is observed beyond the tup zone with the failure geometry changing over from circular to elliptical form as the .reinforcement is increased in the course direction. 


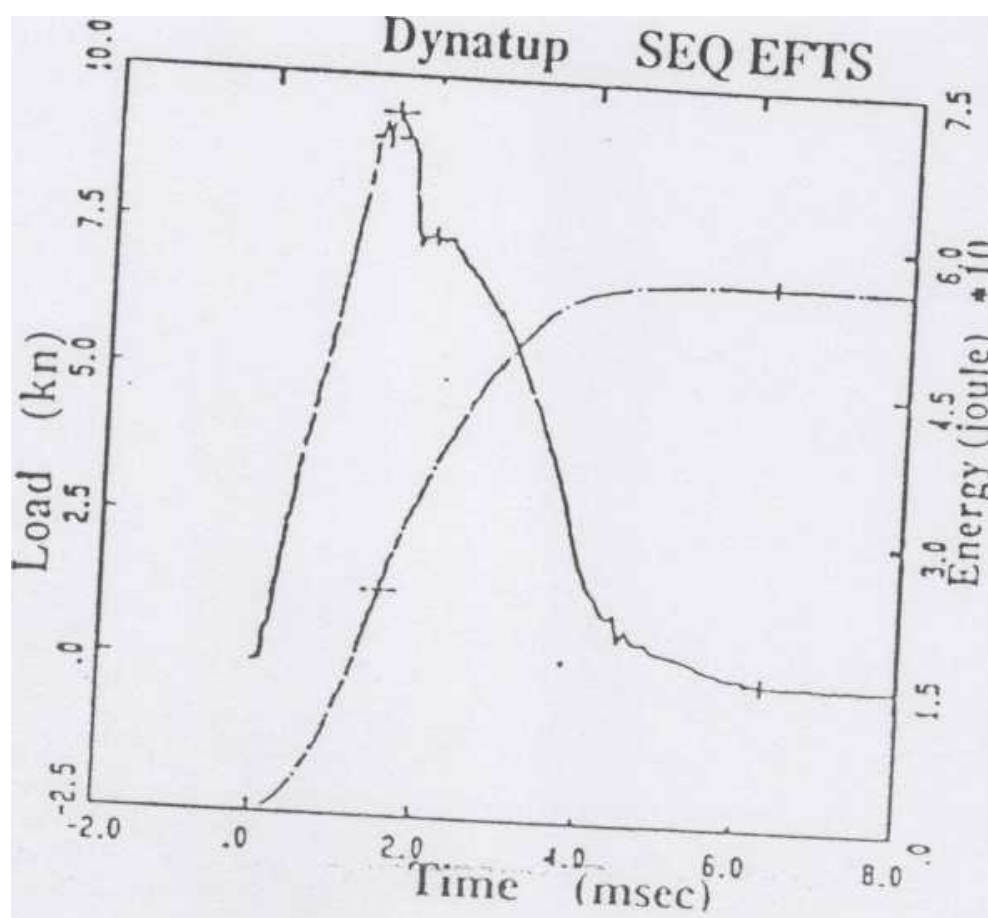

(a) $\left[45 / 0_{5} / \mathrm{s}\right.$

a

SE EFTS

i 0

$.15 \quad \mathbf{i}$

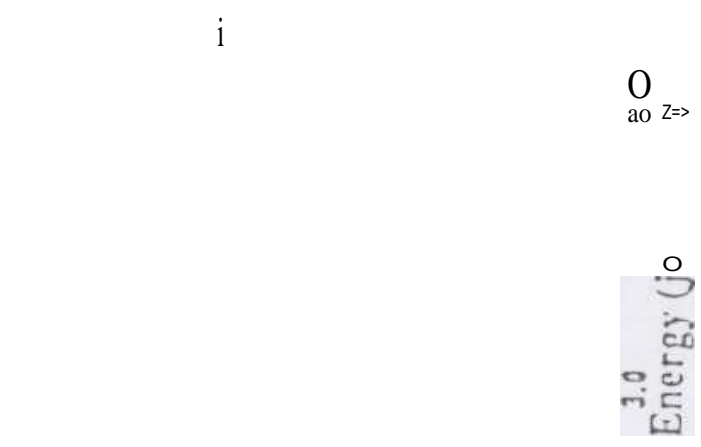

$r$

$.15 \quad \mathbf{i}$

1.5

3.0

Time (cosec)

4.5

$6.0^{\mathbf{o}}$

(b) $\left[0 / 45 / 0_{4}\right]_{5}$

Figure 2. Load-energy traces of woven fabric composites with varied lay-up sequences obtained from Dynatup Instrument: (a) $\left[45 / O_{5} \mathrm{~J}_{5}\right.$, $(03 / 45 / 02)_{s}$

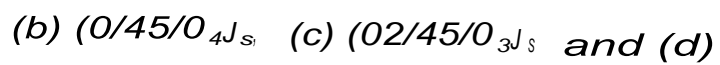




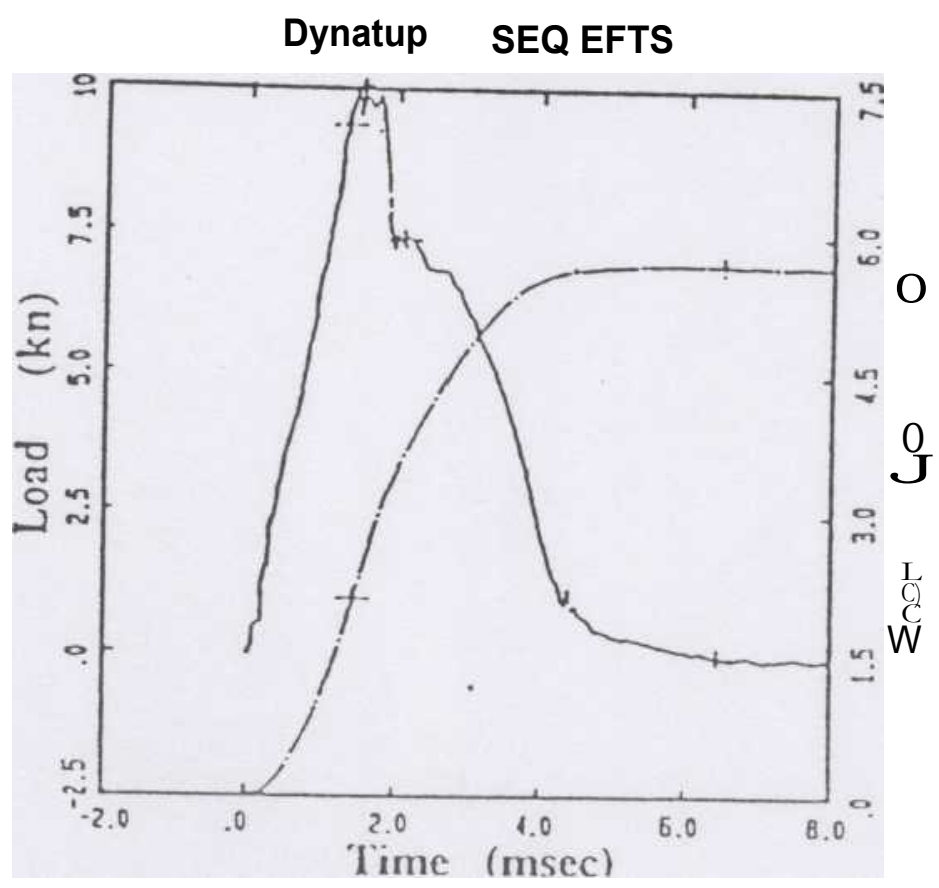

(c) $\left[\mathrm{O}_{2} / 45 / \mathrm{O}_{3}\right]$,

\section{Dynatup SEQ EFTS}

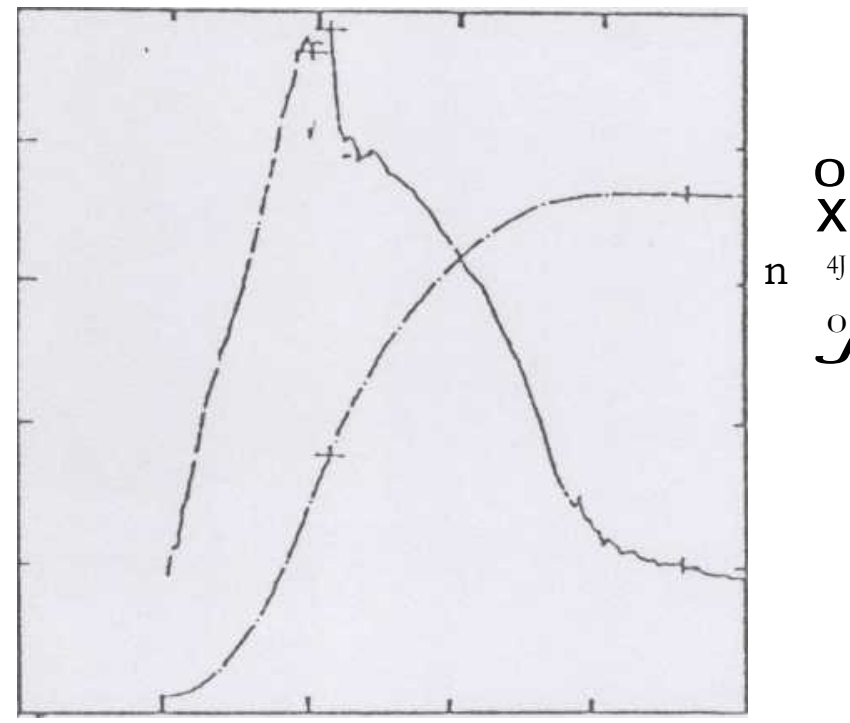

(d) $\left[0_{3} 14510_{2}^{1} \mathrm{~s}\right.$

Figure 2 (continued). Load-energy traces of woven fabric composites with varied lay-up sequences obtained from Dynatup Instrument: (a) [45/0 5 , (b) $\left(0 / 45 / 0_{4}{ }_{5}\right.$, (c) $\left.10_{2} / 45 / 0_{3}\right]$, and (d) $103 /{ }^{4} 5 /{ }^{0} 21$. 


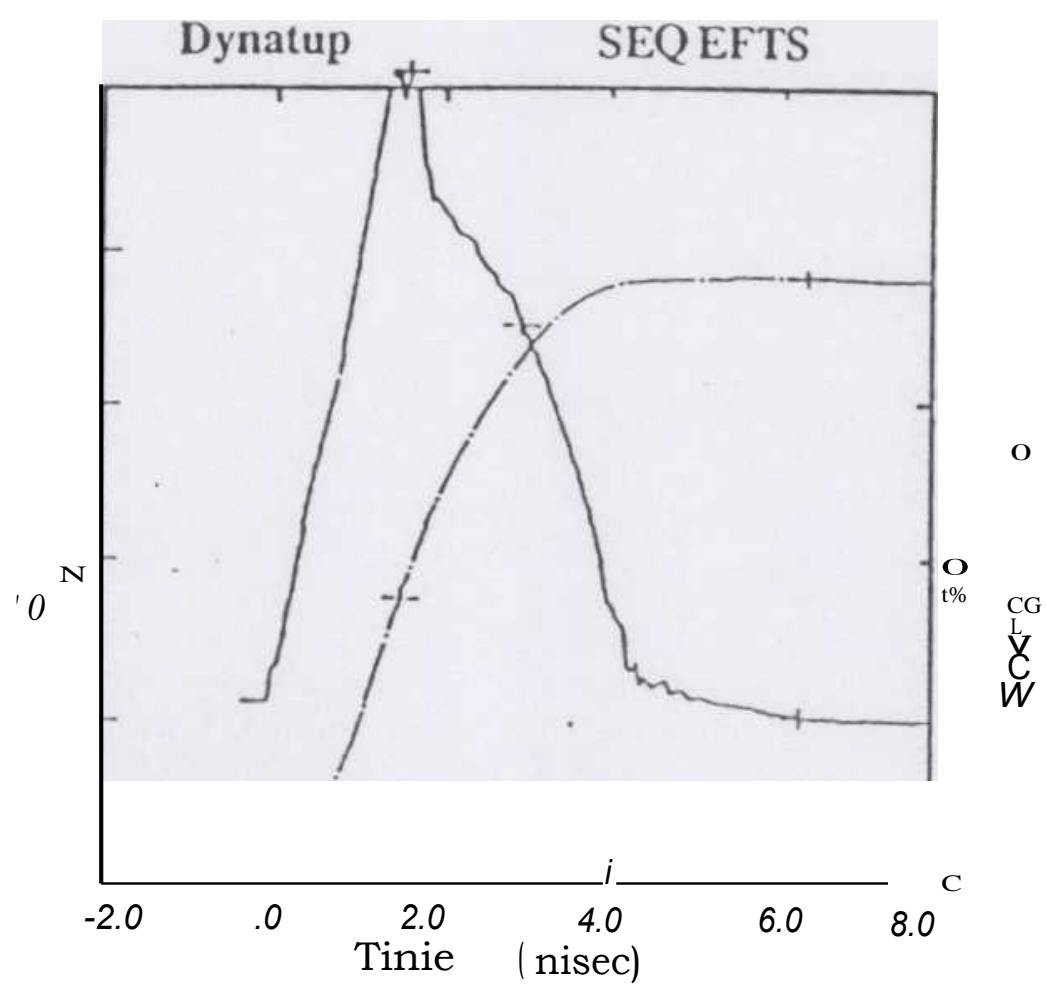

(a) $10,1^{4} 5101$,
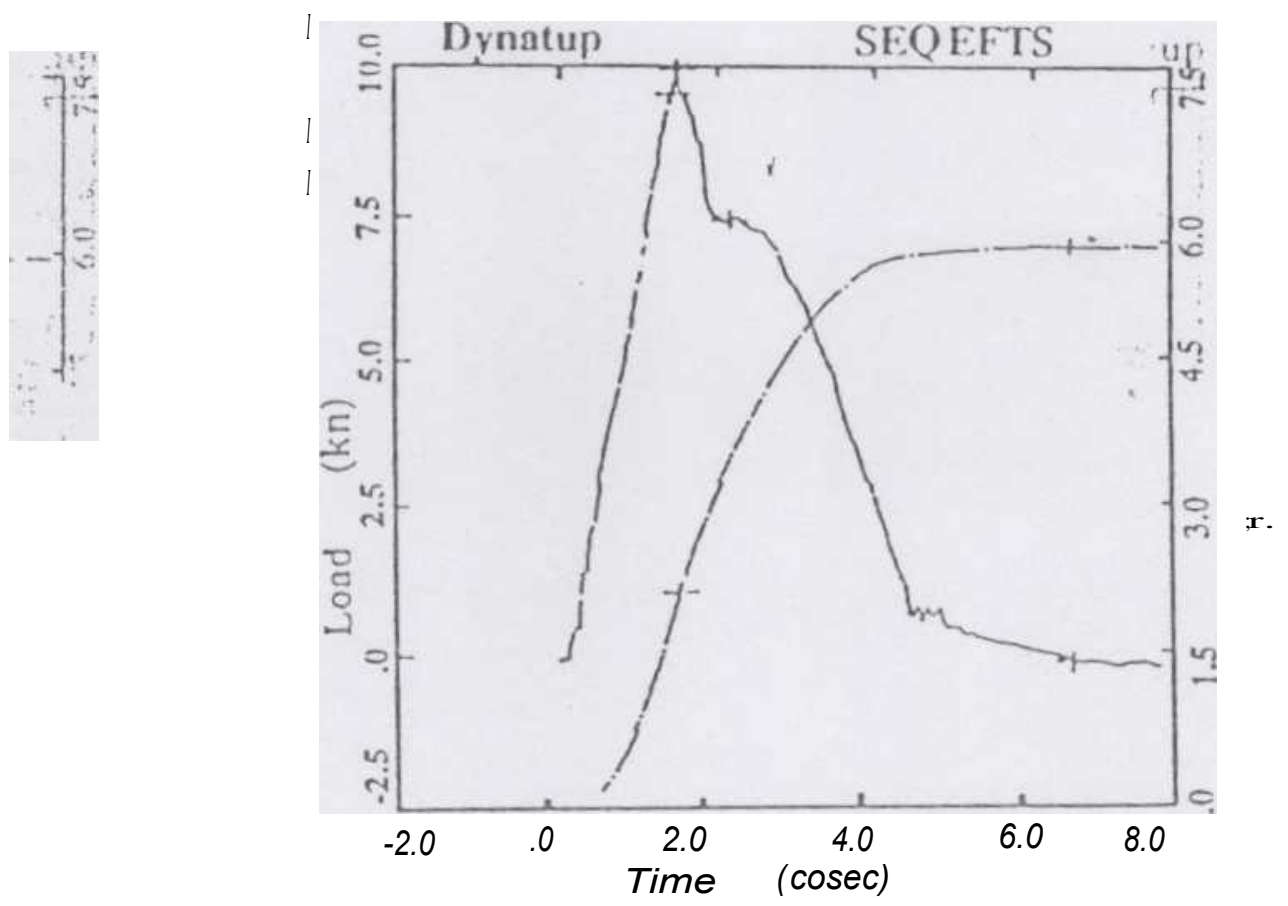

(b) $\left[\mathrm{O}_{5} / 45\right]_{5}$

Figure 3. Load-energy traces of woven fabric composites with varied lay-up sequences obtainedfrom Dynatup Instrument: (a) $\left.10_{4} 14510\right]$, (b) 10,145], (c) [0 6], and (d) 1021 - 3011 45], 


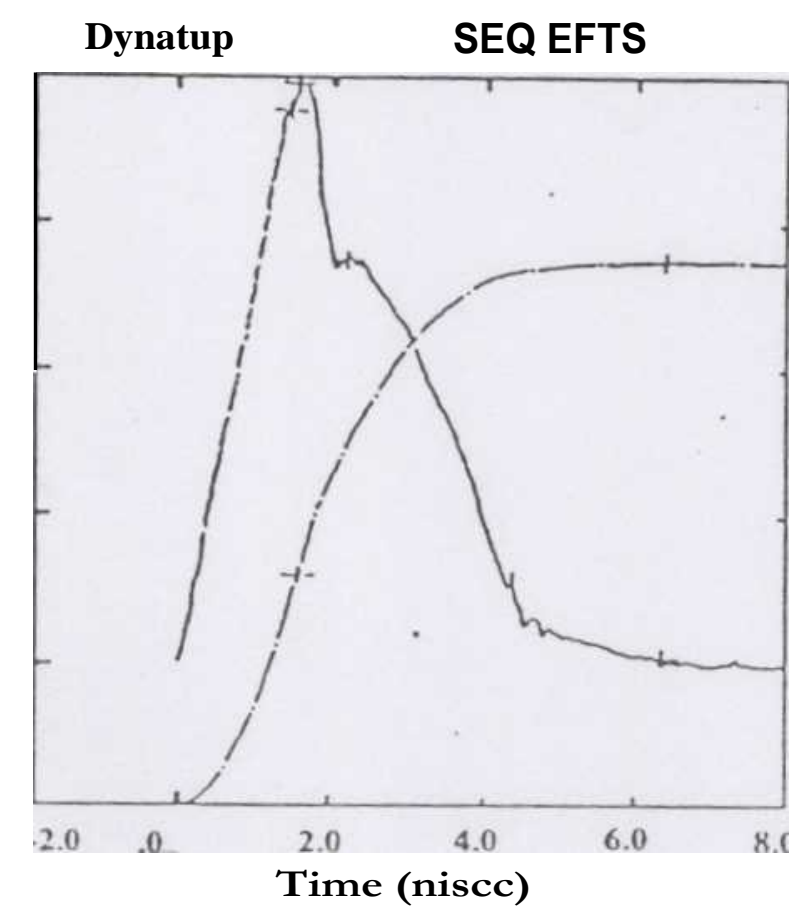

(C) $(061 \mathrm{~s}$

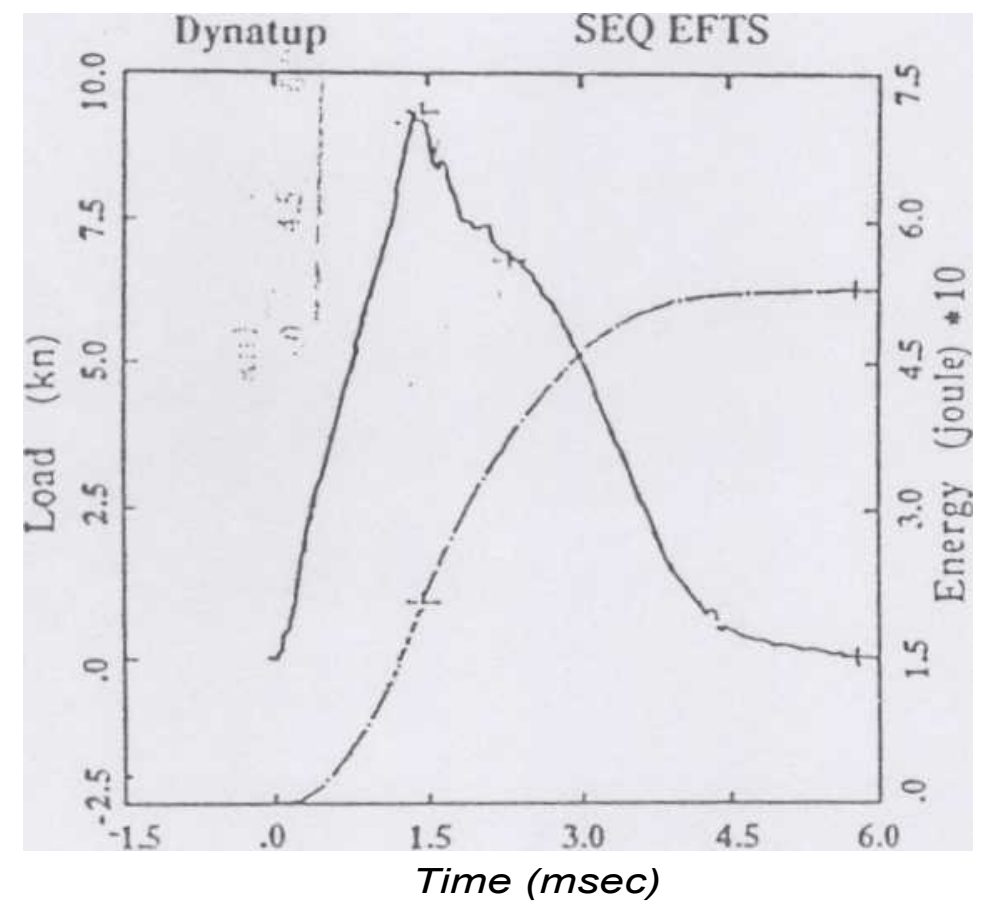

(d) $102 / \pm 3^{0} / \pm{ }^{45} 15$

Figure 3 (continued). Load-energy traces of woven fabric composites with varied lay-up sequences obtained from Dynatup Instrument: (a) $\left(0_{4} / 45 / 01_{5}\right.$, (b) $/ 0_{5} / 451_{5}$, (c) ${ }_{(0615}$ and (d) [0 $21--301--451$,- 


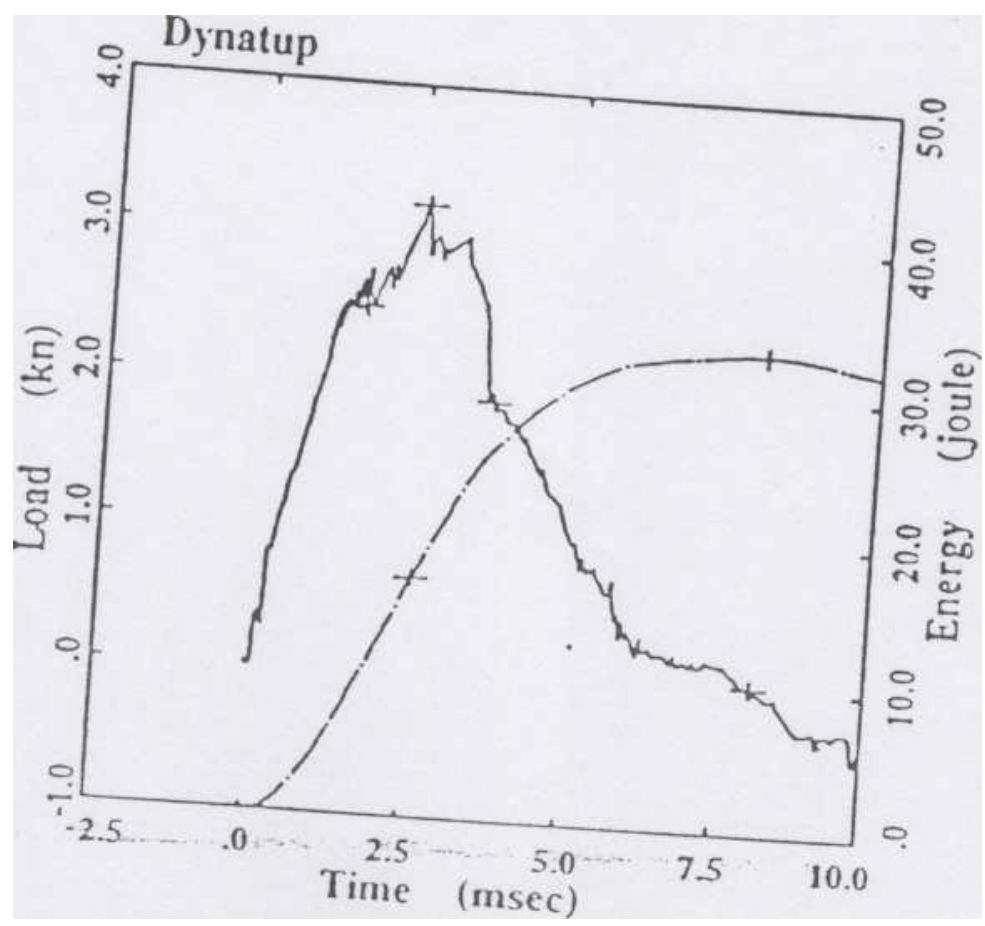

(a) Plain

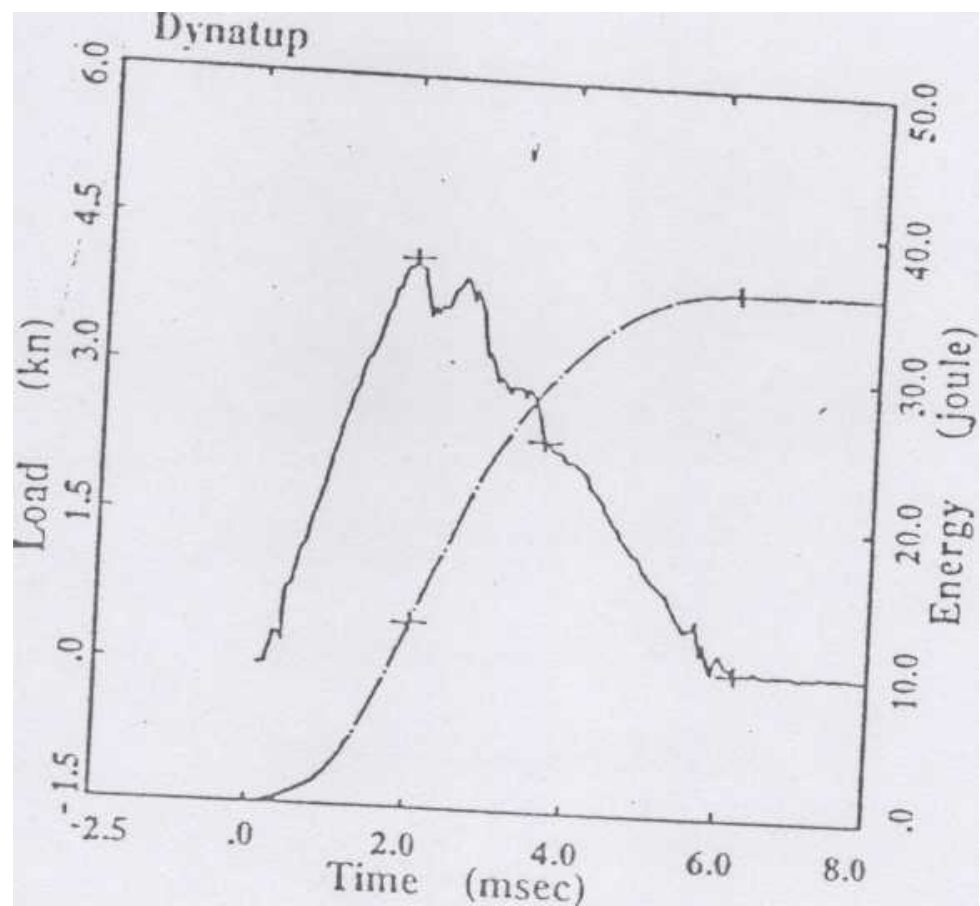

(b) 1800 Tex

Figure 4. Load-energy traces of knit laminates with varying reinforcements in the course diFextion obtained from Dynatup Instrument: (a) plain, (b) 1800 Tex, (c) 3600 Tex, and (d) 5400 


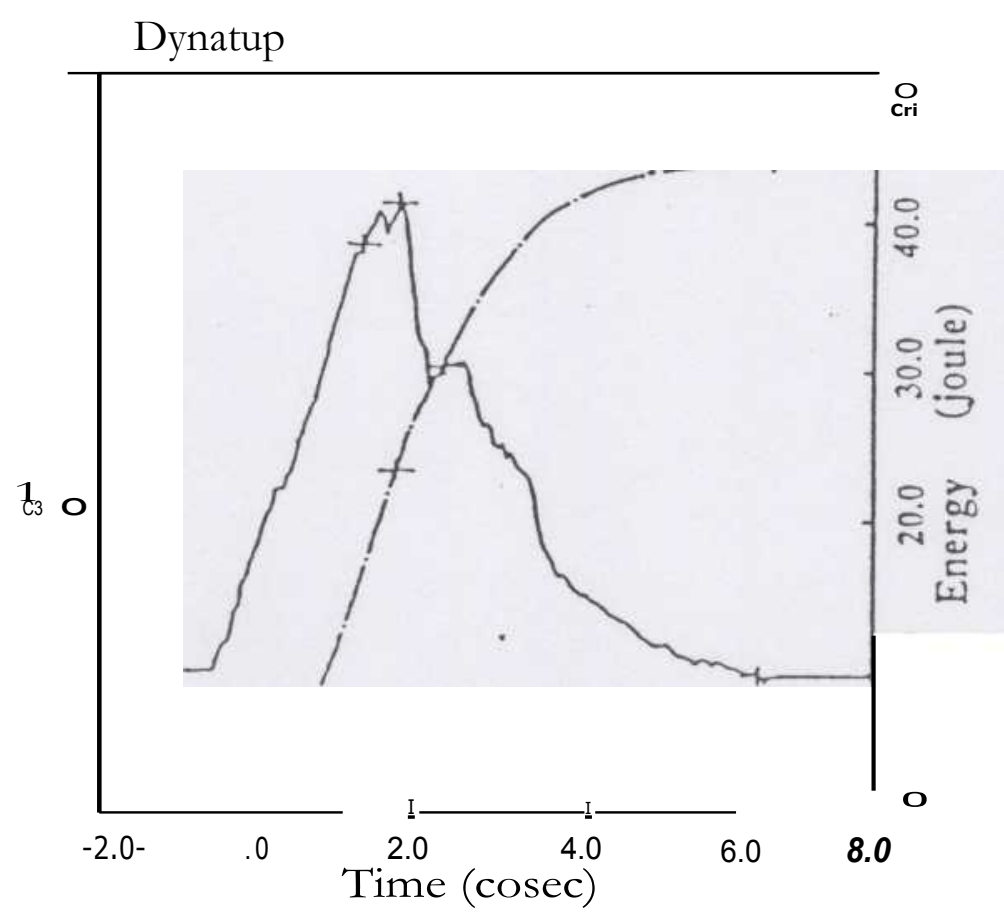

(c) $3600 \mathrm{Tex}$

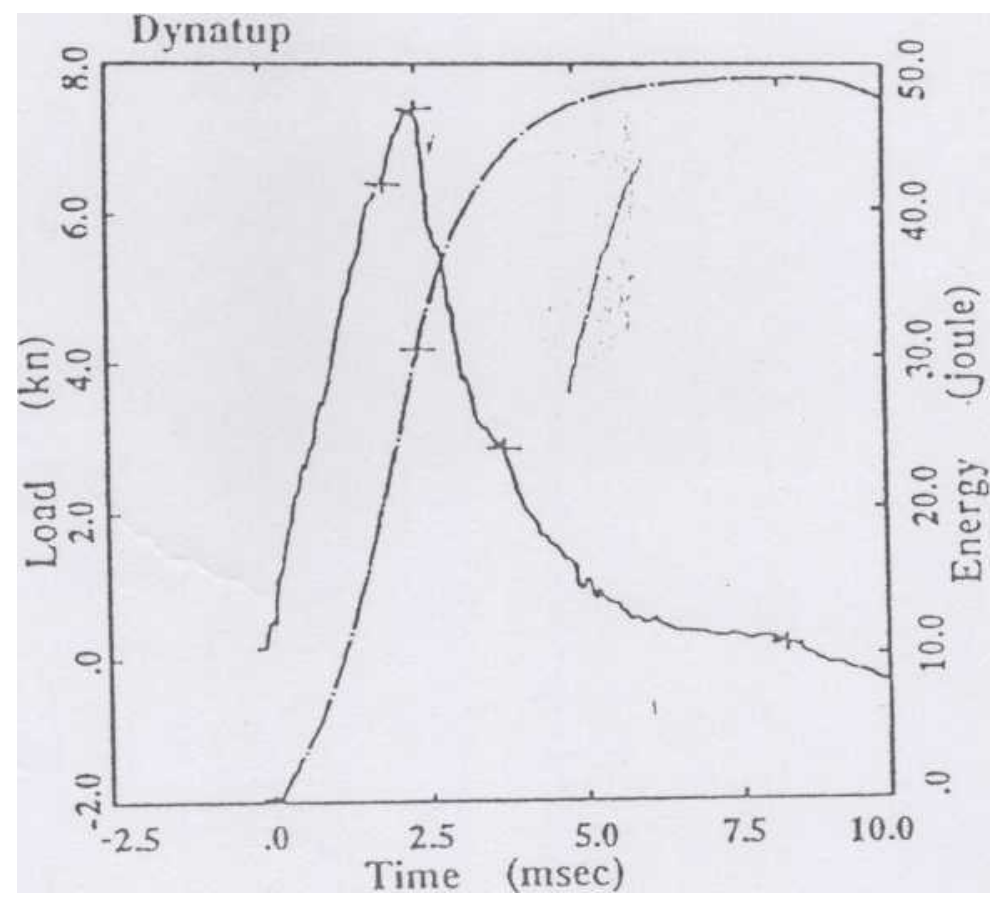

(d) 5400 Tex

Figure 4 (continued). Load-energy traces of knit laminates with varying reinforcements in the course direction obtained from Dynatup Instrument: (a) plain, (b) 1800 Tex, (c) 3600 Tex, and (d) 5400 Tex. 


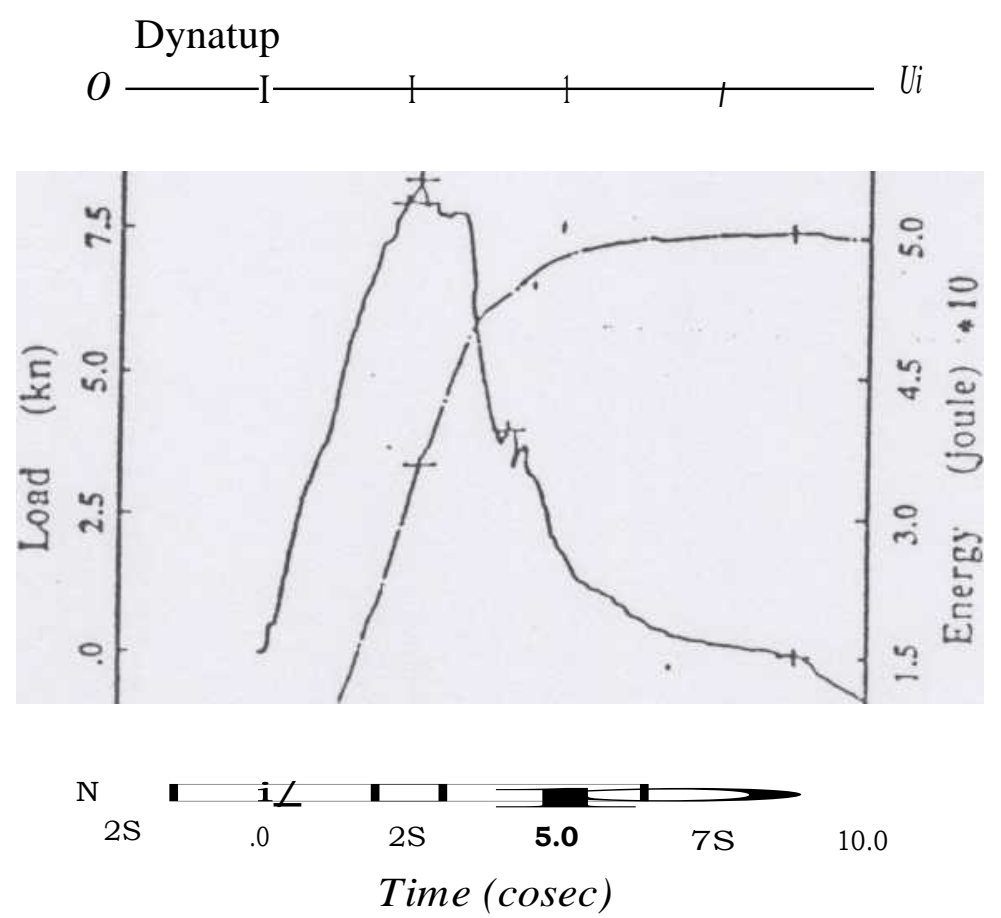

(a) $7200 \mathrm{Tex}$

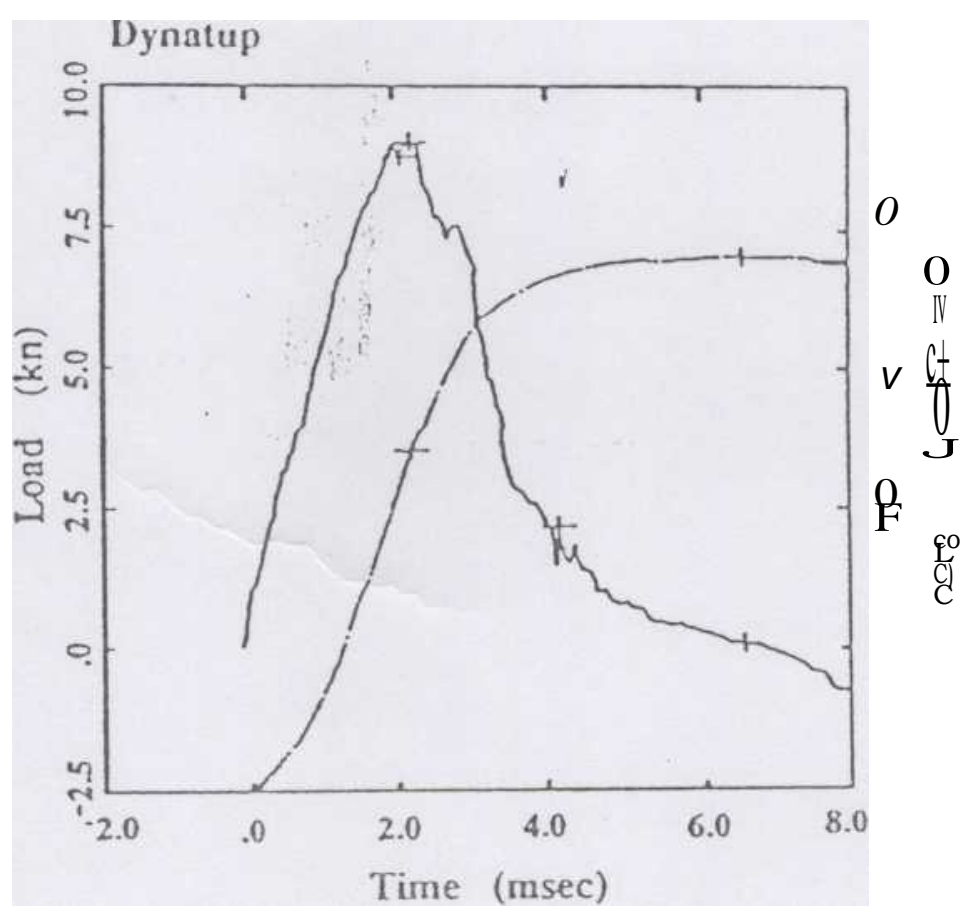

(b) 9000 Tex

Figure 5. Load-energy traces of knit laminates with varying reinforcements in the course direction obtained from Dynatup Instrument: (a) 7200 Tex and (b) 9000 Tex. 


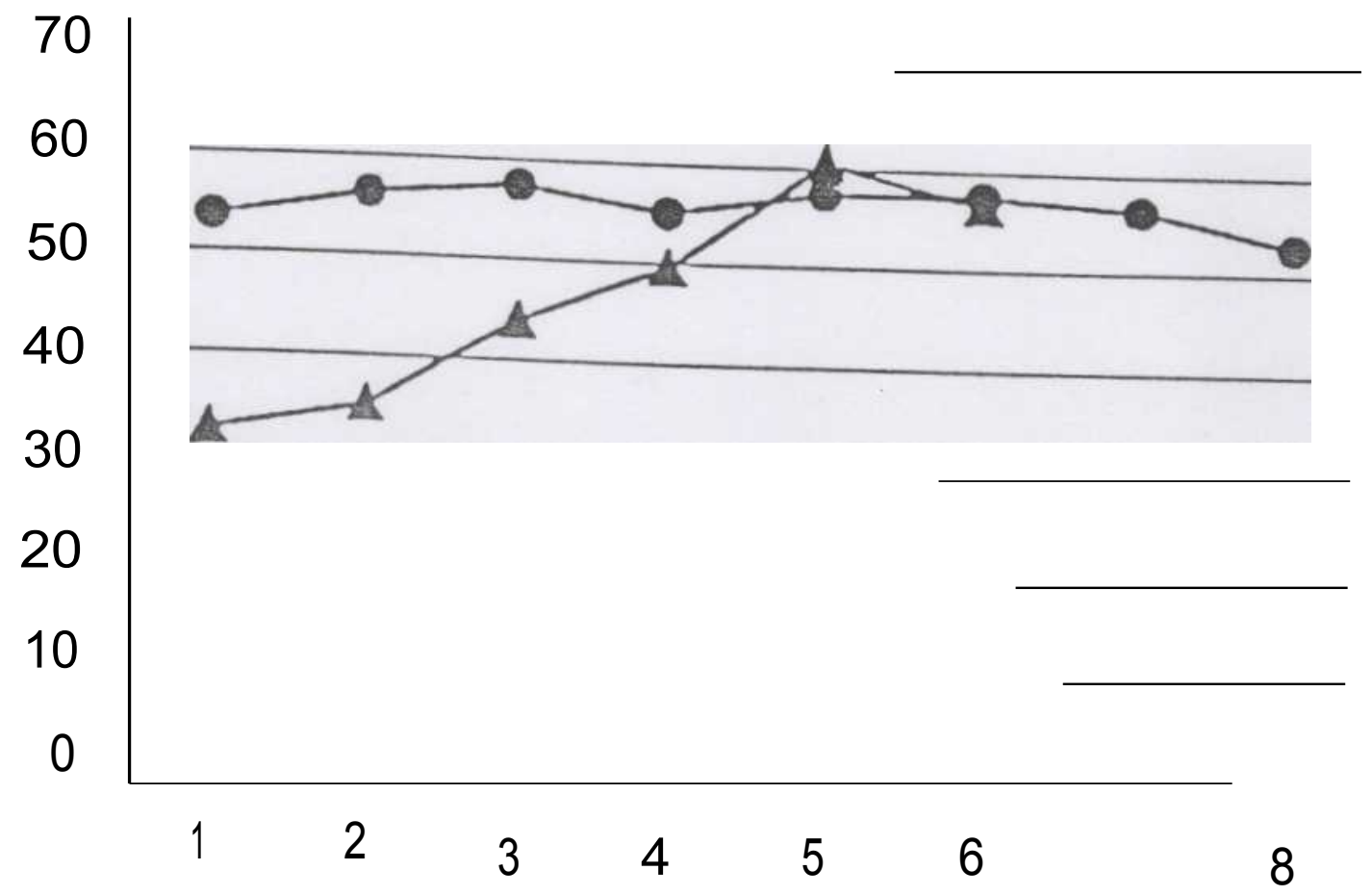

(a)

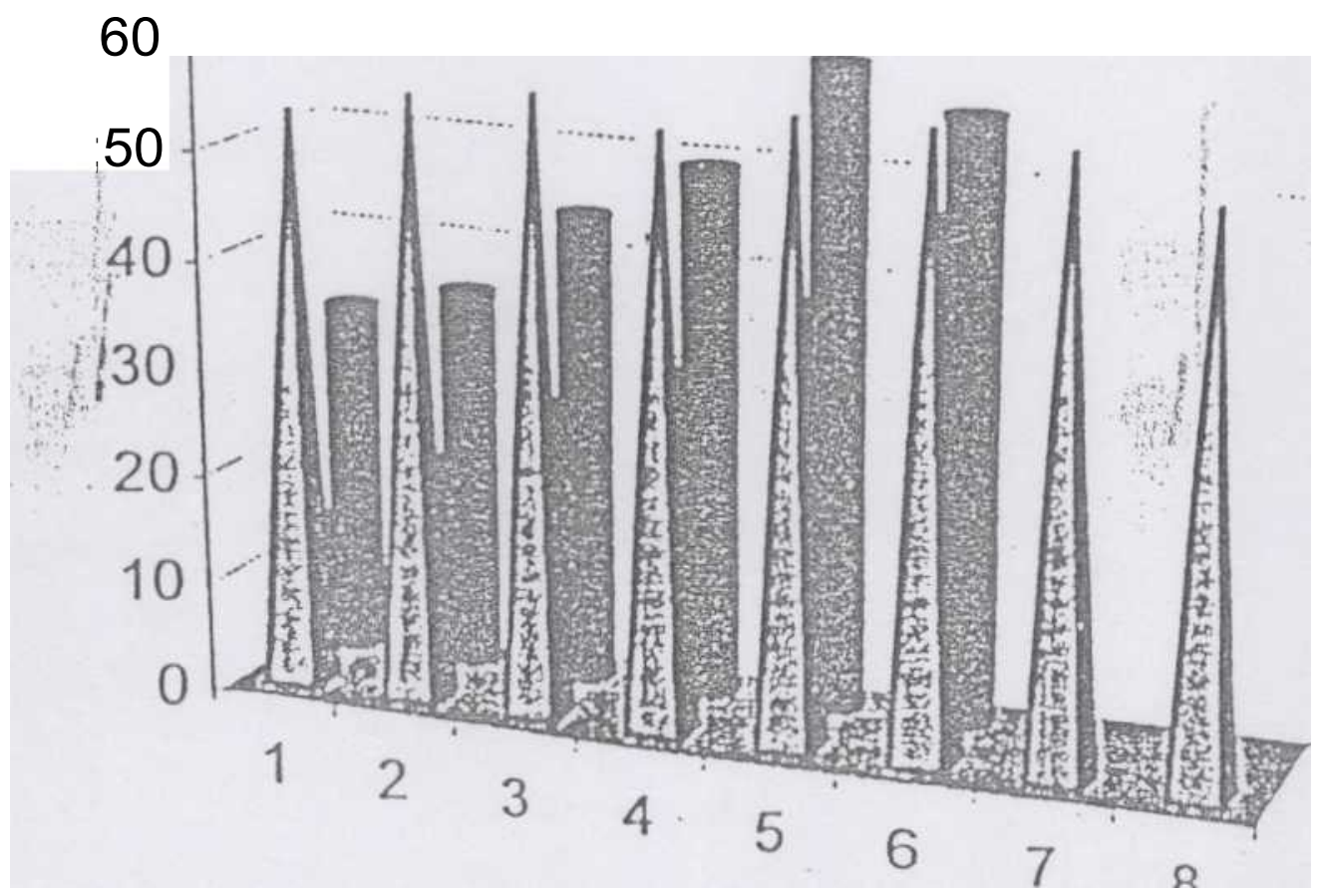

(b)

Figure 6. Plots of the total energy absorbed by the laminates (incident energy= 66.6 :t 0.3 J). 1(a) plots and (b) column diagrams] X-axis: For knits 1-6 represents Plain, 1800, 3600, 5400, 7200 and 9000 Tex reinforcements respectively in that order. For woven fabric composites 1-8 represents $\left.\left.\left[451 O_{5}\right]_{5},\left[0145 / O_{4}\right] 5,10_{2} / 45 / O_{3}\right]_{5}, 10_{3} 145 / O_{2}\right]_{5},\left(O_{4} 145 / O\right]_{5},\left[0_{5} / 45\right]_{5}, 10_{6} 1_{\mathrm{s}}$ and $\left(\mathrm{O}_{2} / 33 \mathrm{O} !^{\prime} \cdot 45\right]_{5}$ lay-up sequences respectively in that order and $y$-axis: energy in joules: - woven fabric composite laminates and A knit laminates. 


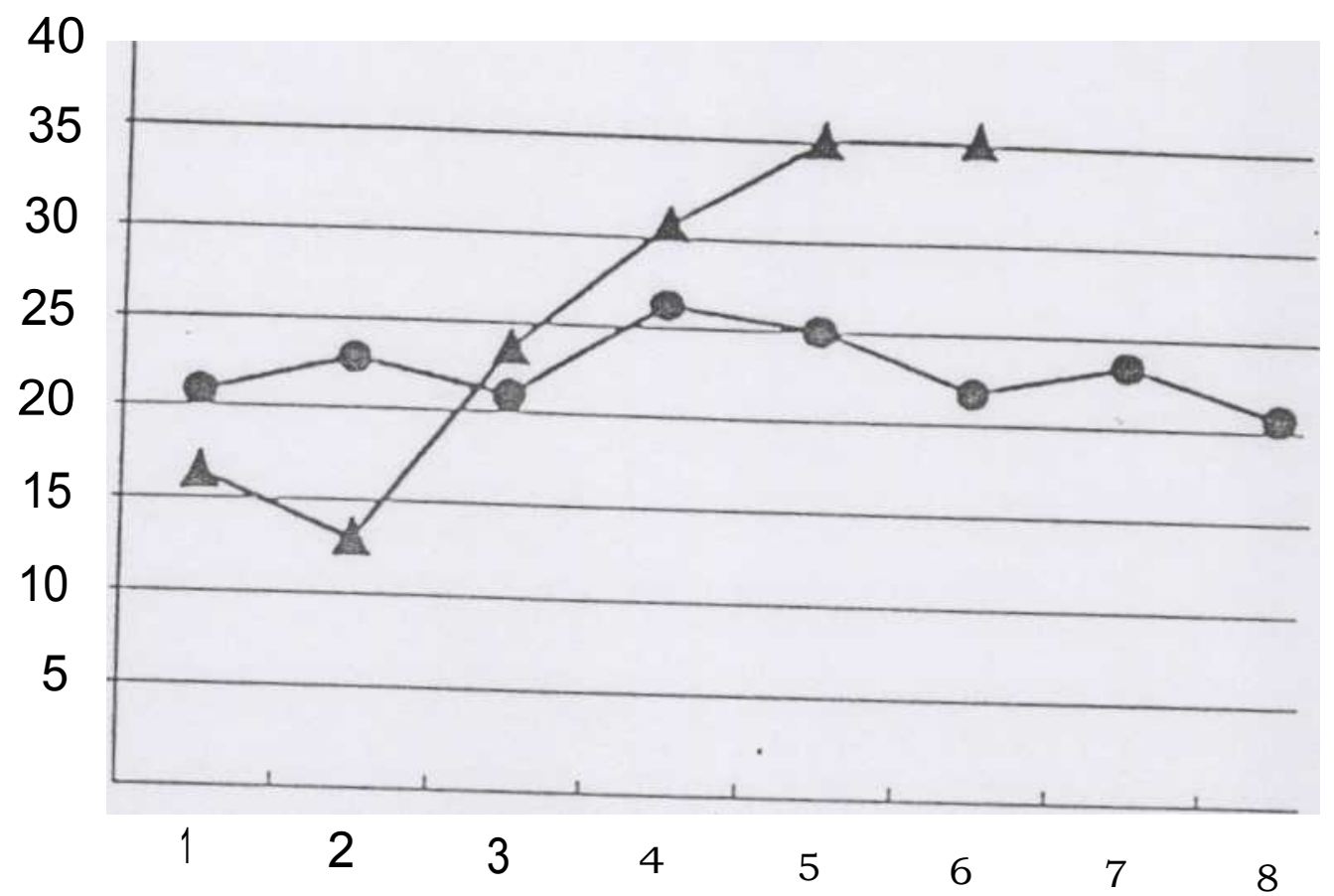

(a)

40

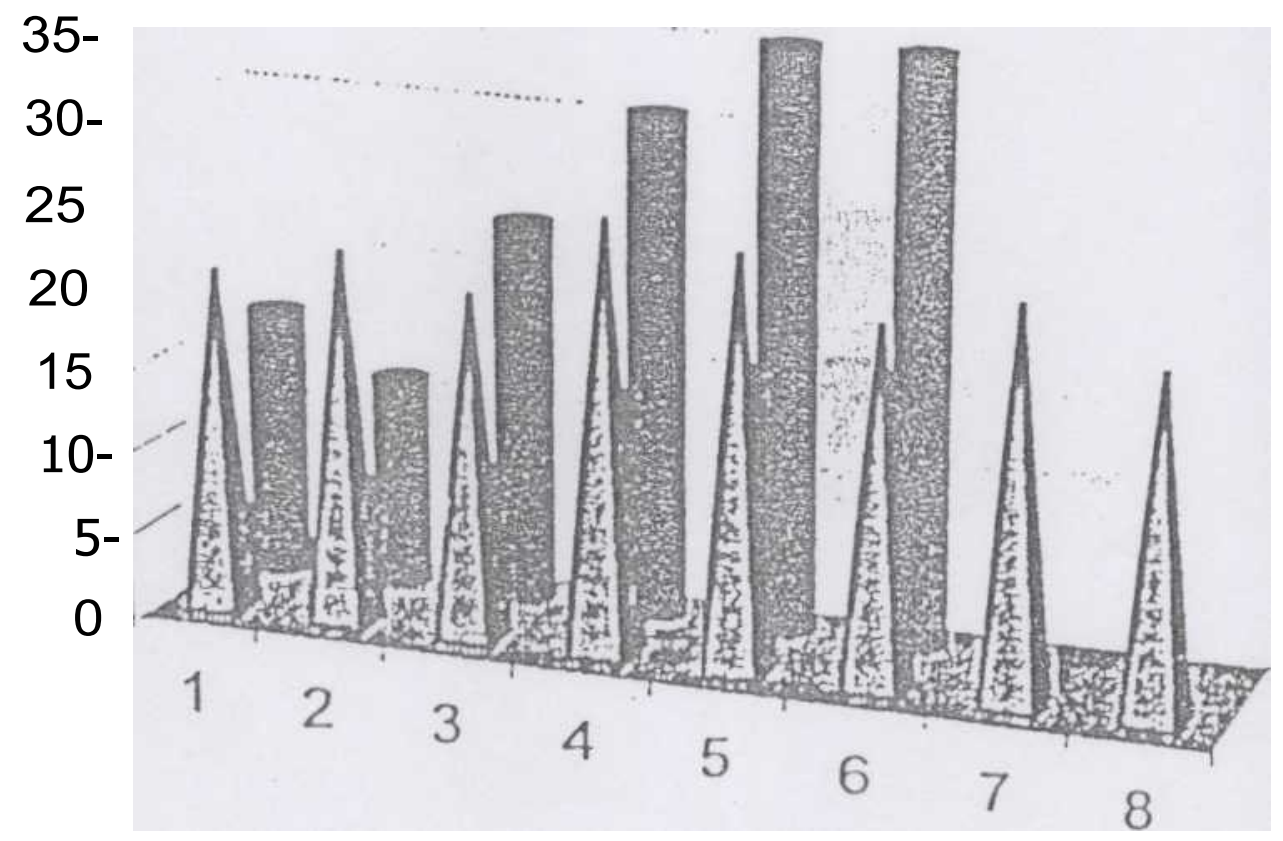

(b)

Figure 7. Plots of the energy absorbed during maximum load point (MLP) by the laminates (incident energy $=66.6 \mathrm{~F} 0.3 \mathrm{~J}$ ). [(a) plots and $(b)$ column diagrams] $X$-axis: For knits $1-6$ represents plain, 1800, 3600, 5400, 7200 and 9000 Tex reinforcements respectively in that order For woven fabric composites $1-8$ represents $\left[45 / O_{5}\right]$, $\left(O / 45 / O_{4}\right)_{5}, \quad\left(0_{2} 145 / 0_{375}\right.$, $\left.10_{3} 14510_{2}\right)_{5},\left(0_{4} 14510\right]_{5},\left[0_{5} 145\right)_{5}\left(0_{5} 7_{5}\right.$ and $\mathrm{jO}_{2} 1^{\top} 301_{-}^{-} 45 \mathrm{~J}_{5}$, lay-up sequences respectively in that order and y-axis: energy in joules: - woven fabric composite laminates and $\bullet$ knit laminates. 


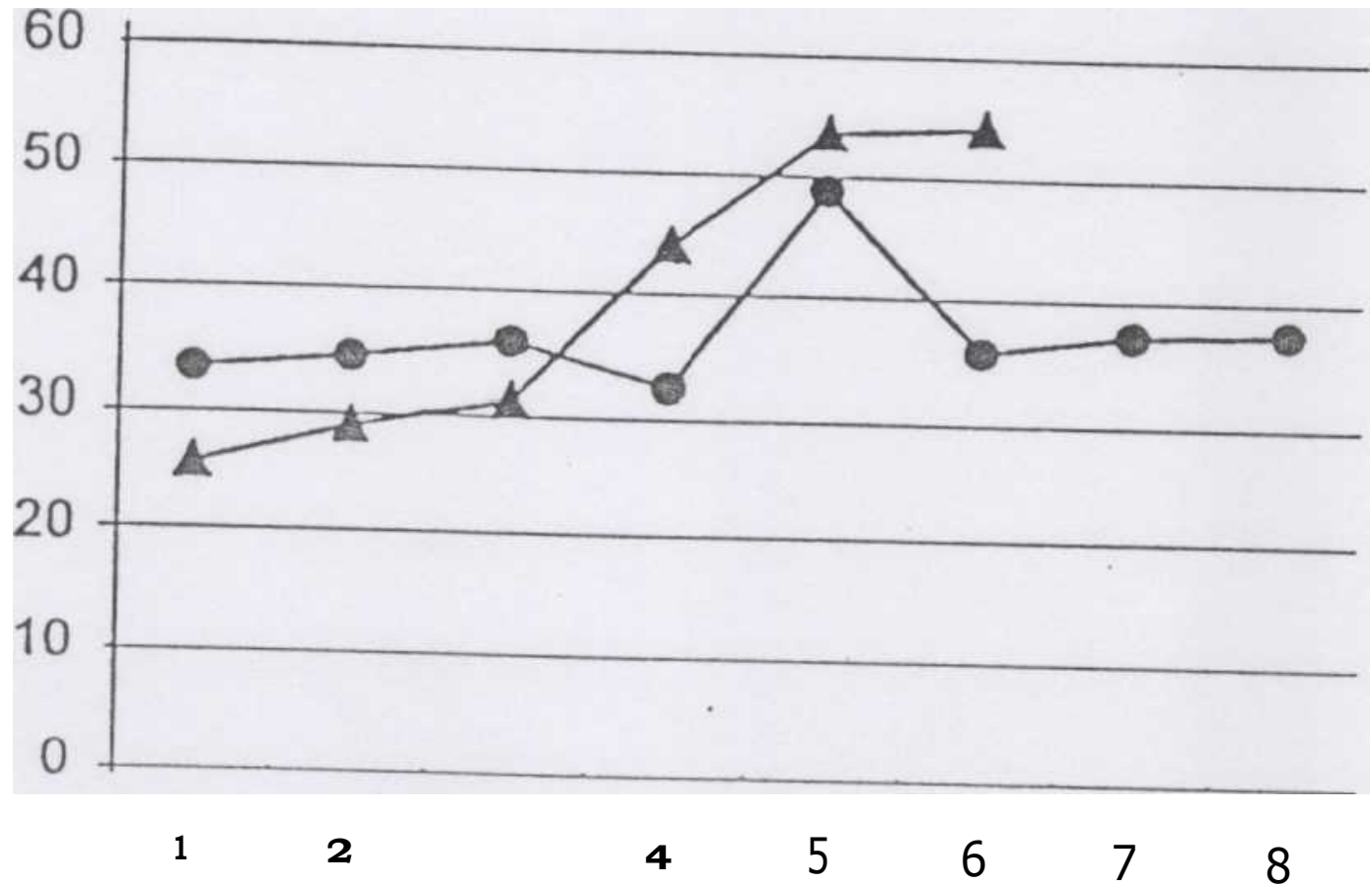

(a)

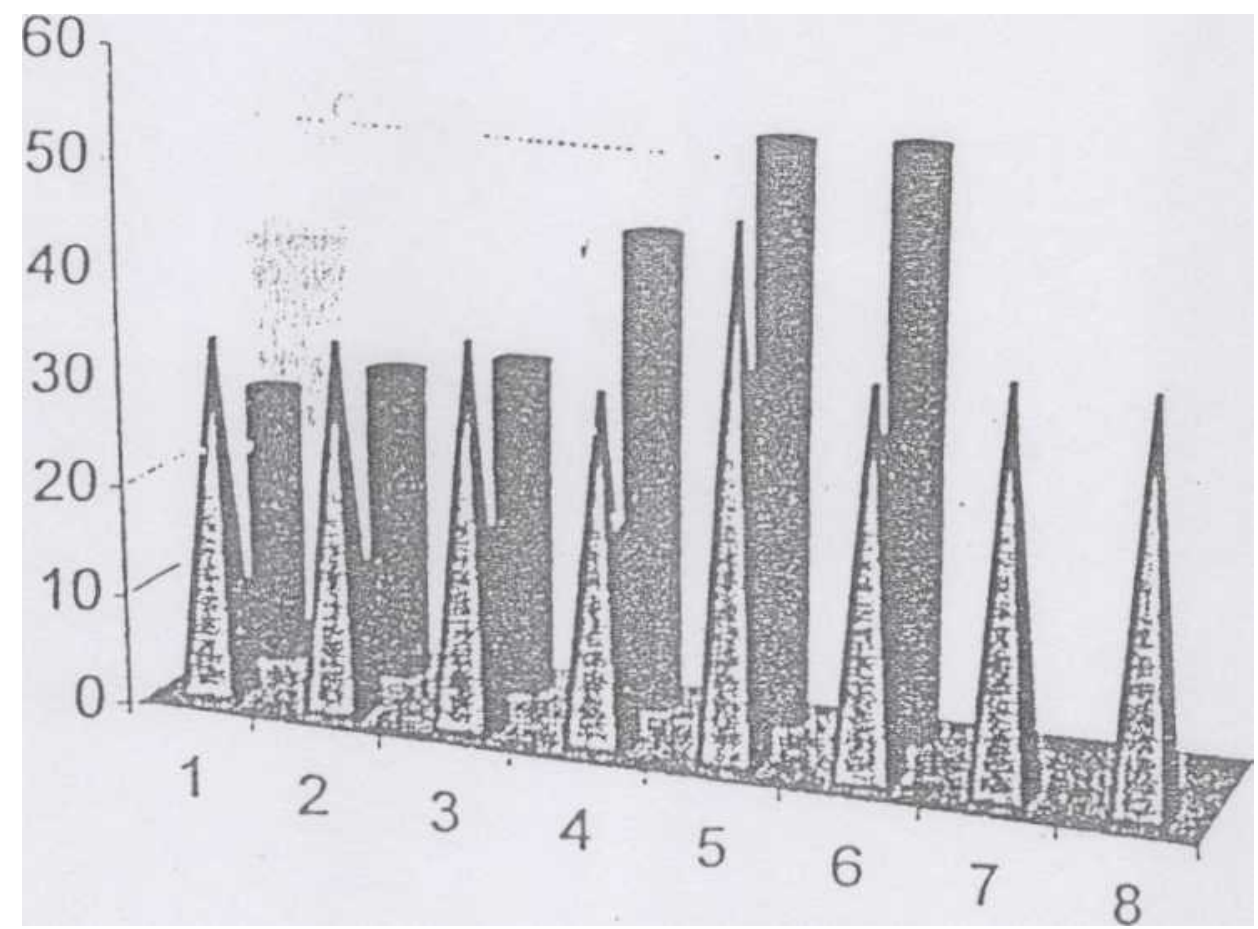

(b)

Figure 8. Plots of the energy absorbed during failure point (FP) by the laminates (incident energy $=66.6 \pm 0.3 \mathrm{~J})$. ((a) plots and (b) column diagrams] $X$-axis: For knits 1-6 represents plain, 1800, 3600, 5400, 7200 and 9000 Tex reinforcements respectively in that order. For woven fabric composites 1-8 represents $\left(45 / 0_{5} J_{5}, \quad\left(014510_{\mathrm{a}} \mathrm{f}_{\mathrm{s}}, \quad 10_{2} 14510_{3}\right)_{5}, \quad\left(0_{3} 145 / 0_{2}\right)\right.$, $(0,14510)_{5},\left(0_{5} 145\right)_{5},\left[\mathrm{O}_{c} J_{s}\right.$ and $\left(\mathrm{O}_{2} 1--301 \pm 45\right]_{s}$ lay-up sequences respectively in that orderand $y$-axis: energy in joules: . woven fabric composite laminates and • knit laminates. 


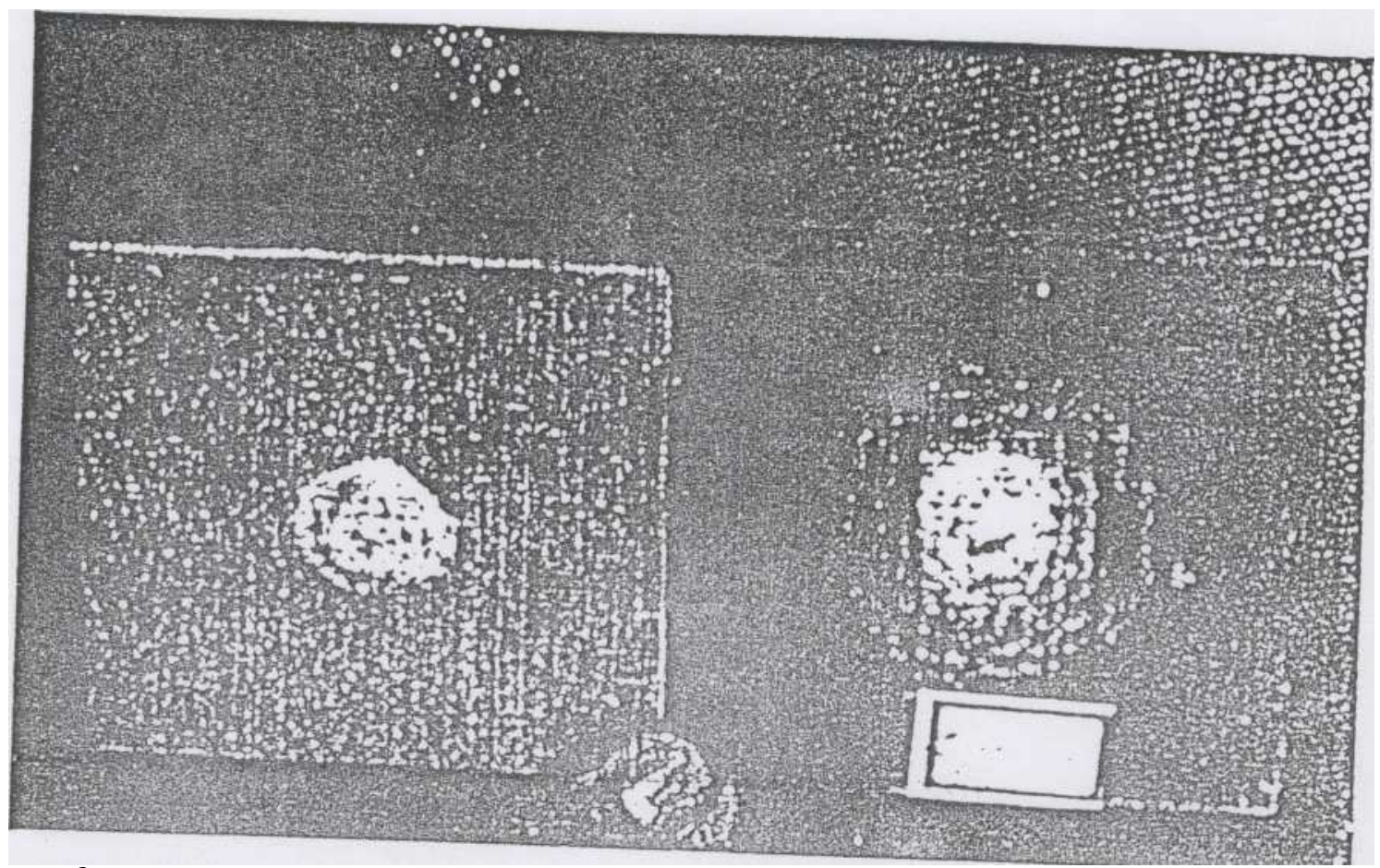

Figure 9. composites. (Note the extensive matrix cracking in the case of knits.)
calch

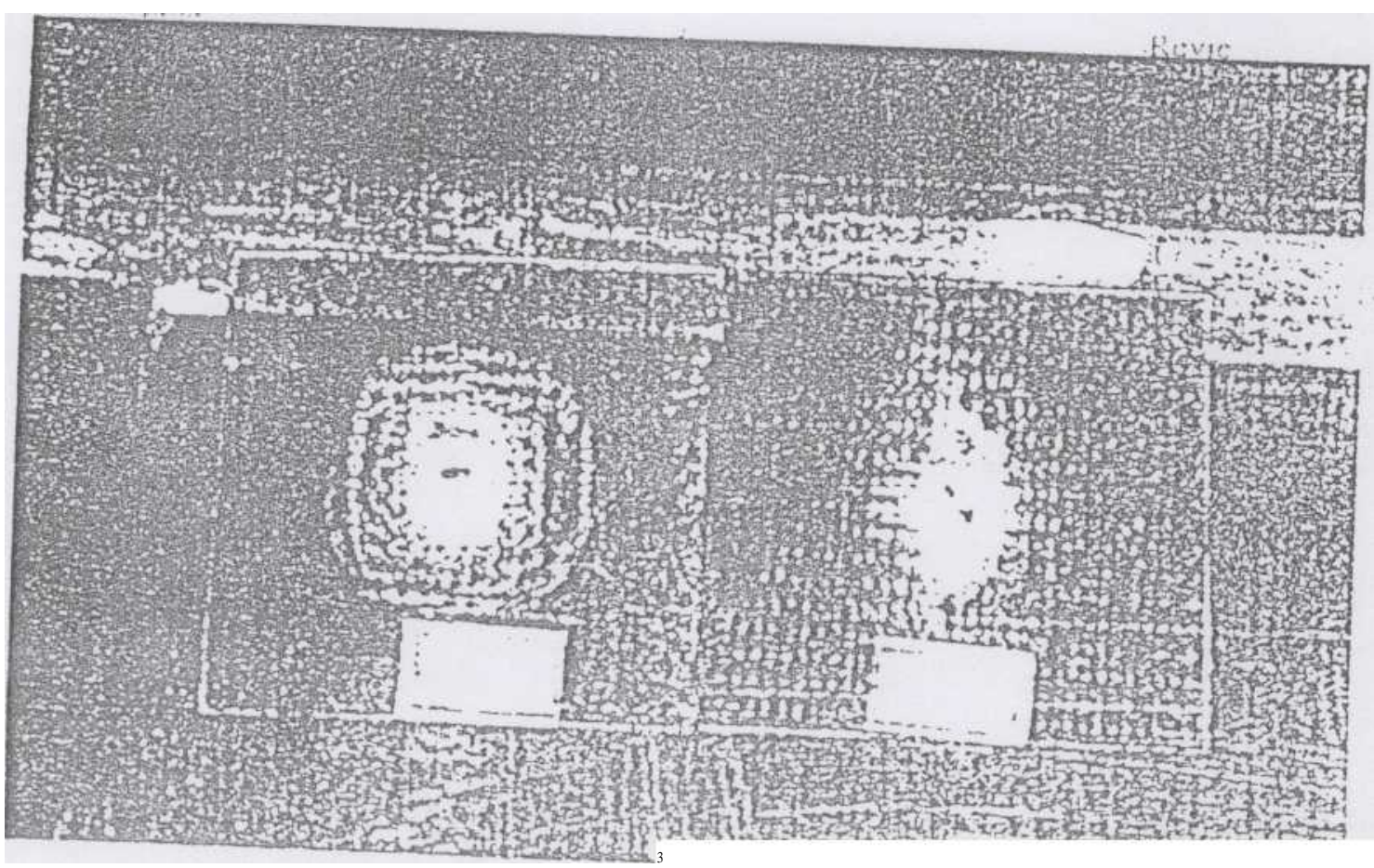

Figure 10.

Tex reinforcementge right). geometry of two extreme cases for knits viz., plain (left) and 9000 


\section{CONCLUSIONS}

- Rib knit preforms with added reinforcements in the course direction have superior energy absorbing capabilities compared to equivalent woven fabric composites.

- As the reinforcement increases, the energy absorbing capability of the panel increases.

- Visible matrix cracking in the case of knits is observed as compared to delamination in the case of wovens in the impact zone.

\section{ACKNOWLEDGEMENTS}

The authors wish to thank Dr. T. S. Prahalad, Director, National Aerospace Laboratories for his support in carrying out the studies. Special thanks are due to our colleagues of FRP-Pilot Plat for their co-operation.

\section{REFERENCES}

N.V. Padaki, V. Prakasha, A. Vani, C.J. Divakar, T. Ananthknshnan and R.M.V.G.K. Rao, "Studies on mechanical behaviour of knittcd glass-epoxy composites.' under communication with Journal of Rcinforced Plastics and Composites.

2. G. Dorcy. S.M. Bishop and P.T. Curbs, "On,Shc impact performance of carbon fibre laminates with epoxy and PEEK matrices," Composites Science and Technology. 1985. Vol. 23. pp 221-237.

3. M.O.W. Richardson and M.J. Wishearb '; \{ evjcw of low-velocity impact properties of compositc materials," Compositcs Part A 27 A, 199(. . . 1 123-1131.

4. S.A. Hitchen and R.M.J. Kemp, "The effects of stacking scquencc on impact damage in a carbon fibre/epoxy compositc;' Composites. 1995. Vol. 26, No. 3.

5. M.F.S.F. Dc Moura. J.P.M. Goncalves. Aj- tarques and P.M.S.T. Dc Castro. "Modelling compression failure after low velocity impact on laminated composites using interface elements; Journal of Composite Materials, 1997. Vol. 31, No. 15. pp. 1462-1479.

6. Z. Tian and S.R. Swanson, "Residual tensile strength prediction on a ply-by-ply basis for laminates containing impact damage;' Journal of Composite Materials, 1992, Vol. 26, No. 8. pp. 1193-1206.

7. H.Y. Choi and F.-K. Chang. "A model for predicting damage in graphitelepoxy laminated composites resulting from low-velocity point impact;' Journal of Composite Materials, 1992, Vol. 26. No. 14, pp. 2134-2169.

8. M.N.G. Nejhad and A. Parvizi-Majidi, "Impact behaviour and damage tolerance of woven carbon fibre-t;einforced thermoplastic composites." Composite. March 1990, Vol. 21, No. 2, pp. 155-168. 